\title{
Assessment of Pain and Associated Comorbidities: A Survey of Real Life Experiences Among Nurses in Italy
}

This article was published in the following Dove Press journal:

Journal of Pain Research

\author{
Chiara Angeletti (iD) \\ Paolo Matteo Angeletti $\mathbb{D}^{2}$ \\ Martina Paesani (D) \\ Cristiana Guetti ${ }^{3}$ \\ Aglaia Gyra (1) ${ }^{2}$ \\ Gianluca Perseo' \\ Alessandra Ciccozzi (D) $)^{2}$ \\ Franco Marinangeli $\mathbb{D}^{2}$ \\ Emma Altobelli (iD) \\ 'Operative Unit of Anaesthesiology, \\ Intensive Care and Pain Medicine, Civil \\ Hospital G. Mazzini of Teramo, Teramo, \\ Italy; ${ }^{2}$ Department of Life, Health and \\ Environmental Sciences, University of \\ L'Aquila, L'Aquila, Italy; ${ }^{3}$ Emergency \\ Department, Intensive Care Unit and \\ Regional ECMO Referral Centre, Azienda \\ Ospedaliero-Universitaria Careggi, \\ Florence, Italy; ${ }^{4}$ Department of Life, \\ Health and Environmental Sciences, \\ Epidemiology and Biostatistics Unit, \\ AUSL Teramo, University of L'Aquila, \\ L’Aquila, Italy
}

Purpose: Pain is a symptom that should be evaluated along with its comorbidities in order to plan an effective holistic treatment strategy involving specific pharmacological interventions, side effect management, psychological support, control of therapeutic effects over time, and dialogue with the patient and their relatives. In this holistic process of caring for patients with pain, nurses play a central role as they deal with suffering patients directly and continuously. The purpose of this study was to evaluate the types of pain identified by nurses in their daily clinical practice and the associated comorbidities (anamnestic history taking) by geographical region and to evaluate the pharmacological strategies used.

Methods: A cross-sectional survey was performed among 696 registered nurses in Italy. Data were collected using an online questionnaire.

Results: There was a significant difference between geographical regions in terms of reports of acute and chronic pain: acute pain was more frequently reported in the South $(63.5 \%)$, while chronic pain was more frequent in the Central region $(32.3 \% ; \mathrm{p}=0.0008)$. Additionally, chronic oncological pain was more frequent in the Northeast $(29.6 \%)$, while chronic nononcological pain was more frequently reported in the Central region $(33.9 \% ; \mathrm{p}=0.0001)$. The underlying pain disorders reported were also different between geographical regions; rheumatic pain (21.8\%) and neurological pain (18.6\%) were more frequent in the Central region, while musculoskeletal pain was significantly more frequent in the South $(43.4 \% ; \mathrm{p}=0.004)$. Anxiety, sleep disorders and somatization were found in acute pain $(60.82 \%, 43.56 \%$ and $53.12 \%$ ), while depression and mood disorders were more frequently detected in chronic pain condition $(\mathrm{p}<0.001)$.

Conclusion: Our study showed differences among Italian regions in pain assessment. Specific education on pain management nursing is essential for nurses. Promotion of optimal nursing care for people affected by pain is the main focus of pain management nursing. Nowadays, nurses should focus on personalized complex care and research in order to improve the patient's quality of life.

Keywords: pain management, nurse education, psychological comorbidities

\section{Introduction}

Pain assessment is much more than a simple quantification of pain by patients. Ensuring safe and effective pain management means conducting an individualized, comprehensive pain assessment, which includes, but is not limited to, determining the intensity of pain reported by the patient. ${ }^{1}$ Pain is a subjective, multidimensional experience, unique to each patient and one of the most universal and pervasive sources of human distress. The
Correspondence: Chiara Angeletti

Civil Hospital G. Mazzini of Teramo,

Piazza Italia I, Teramo 64100, Italy

Tel +390861429320

Fax +390861429319

Email chiara.angeletti@gmail.com 
code of ethics of professional nurses promotes respect for human dignity, which is an essential part of pain management. The core ethical principles in the Code of Ethics for Nurses with Interpretive Statements by the American Nurses Association provide guidance regarding the complex decisionmaking process related to the assessment and management of pain. ${ }^{2}$ Nurses should continually increase their epidemiological knowledge and disseminate the information to facilitate change, redesign care delivery, and promote access to minimize disparities in pain management. ${ }^{3}$

The immediate consequences of chronic pain, aside from the physical pain itself, include mobility limitations and subsequent loss of strength, sleep disorders, immune deficiencies and increased susceptibility to disease, medication dependence, and co-dependence involving family members and other caregivers. ${ }^{4}$ Severe persistent pain can engender a range of significant psychological and social consequences, such as fear, anger, depression, anxiety, and reduced ability to carry out one's social roles as a family member, friend, or employee. ${ }^{5}$ Anxiety and fear are often used synonymously. Although there is some overlap, fear is generally associated with the autonomic arousal necessary for fight or flight reactions and thoughts closely related to immediate danger and escape behaviors, whereas anxiety is a negative mood state more often associated with muscle tension, vigilance, and use of cautious or avoidant behaviors in preparation for future danger. ${ }^{6}$

Several issues about nurse education remain unsolved; these issues have been covered by Italian Law 38/2010, such as teaching in universities at all levels of education and research development ("Instructions for the access to palliative care and pain therapy"). The aims of this study were to report on (i) the types of pain identified by nurses in their daily clinical practice and the associated comorbidities (based on physician or nurse history taking) by geographical region; (ii) the pharmacological strategies used; and (iii) associated comorbidities by pain type.

\section{Methods}

The study was an online cross-sectional survey performed from October 1, 2013 to September 30, 2014 among Italian registered nurses. The study investigated their perception, engagement, and awareness about pain management.

Among the 422,875 registered nurses in the whole of Italy, 696 (aged 22-63 years) from all regions of Italy took part in the survey. The required sample size was estimated using the following parameters: sample error $=0.04$, event occurrence proportion $\mathrm{p}=0.5$ (in case of maximum variability), and level of confidence $(1-\alpha)=0.95$. There were 193 males, aged $40.16 \pm 9.5$ years (mean \pm standard deviation), and 503 females, aged $41.69 \pm 9.3$ years.

Differences between four geographical regions (the Northwest, Northeast, Central, and South regions, defined by the National Institute of Statistics [ISTAT]) were assessed. Data normality was assessed using the KolmogorovSmirnov test. The Kruskal-Wallis test was applied to interval and ordinal variables. A $p$ value $<0.05$ was considered statistically significant. SAS software was used for the statistical analyses.

The data were collected using an anonymous online questionnaire that was approved and validated by the Paolo Procacci Foundation (FPP), Italian Association for the Study of Pain (AISD), and National Federation of Nurses Colleges (IPASVI). The questionnaire included 34 multiple-choice questions, which had been validated in a pilot study. The questionnaire was available via the websites of the abovementioned organizations (www.aisd.it, www.fondazionepao loprocacci.org, www.ipasvi.it, and www.painnursing.it). Additionally, members of the abovementioned scientific societies and the professional committee (IPASVI) were invited to fill in the questionnaire via a dedicated link sent to them in email newsletters, using email addresses from the membership databases of the scientific societies and IPASVI. The questionnaire was also promoted on major social networks (Facebook, Twitter, and LinkedIn).

The questionnaire collected data, which have been previously published [5], on the following factors: demographic variables (gender, age, and city) and professional variables (department, current employment, attendance of training courses focused on pain management, types of courses [meetings, symposia, and online courses], degree of validity/efficacy of the courses, and approval rating of the courses). The current study investigated the questionnaire data on the following factors: daily management of patients with pain, types of pain, disorders underlying the pain, types of drugs, administration routes, adjuvants, and comorbidities associated with the pain.

\section{Result}

\section{Pain Types, Underlying Disorders, and Comorbidities}

The distribution of the participants in the four geographical regions has been reported in a previous paper. ${ }^{7}$ Table 1 shows the geographical distributions of pain type (acute, chronic, and oncologic), frequency of each pain type, 
Table I Geographical distribution of type, frequency, site of pain comorbidity pathologies associated with non-oncological pain

\begin{tabular}{|c|c|c|c|c|c|c|}
\hline Variable & $\begin{array}{l}\text { Total Responders No. } \\
\text { (\%) }\end{array}$ & $\begin{array}{l}\text { North-West No. } \\
\text { (\%) }\end{array}$ & $\begin{array}{l}\text { North-East No. } \\
\text { (\%) }\end{array}$ & $\begin{array}{l}\text { Centre No. } \\
(\%)\end{array}$ & $\begin{array}{l}\text { South No. } \\
\text { (\%) }\end{array}$ & $\mathbf{p}$ \\
\hline \multicolumn{7}{|c|}{ Type of pain in routine clinical practice } \\
\hline $\begin{array}{l}\text { Acute pain } \\
\text { Chronic pain } \\
\text { Both }\end{array}$ & $665(95.5)$ & $\begin{array}{l}83(49.1) \\
40(23.7) \\
46(27.2)\end{array}$ & $\begin{array}{l}94(44.1) \\
59(27.79 \\
60(28.1)\end{array}$ & $\begin{array}{l}47(37.9) \\
40(32.3) \\
37(29.8)\end{array}$ & $\begin{array}{l}101(63.5) \\
24(15.1) \\
34(21.3)\end{array}$ & 0.0008 \\
\hline \multicolumn{7}{|c|}{ Which is the most frequent type of pain in your routine clinical practice? } \\
\hline $\begin{array}{l}\text { Chronic non-oncological } \\
\text { pain } \\
\text { Chronic oncological } \\
\text { pain } \\
\text { Acute pain }\end{array}$ & $665(95.5)$ & $\begin{array}{l}40(23.7) \\
37(21.9) \\
92(54.4)\end{array}$ & $\begin{array}{l}60(28.1) \\
63(29.6) \\
90(42.2)\end{array}$ & $\begin{array}{l}42(33.9) \\
32(25.8) \\
50(40.3)\end{array}$ & $\begin{array}{l}25(15.7) \\
31(19.5) \\
103(64.8)\end{array}$ & 0.0001 \\
\hline \multicolumn{7}{|c|}{ Pathologies associated with non-oncological pain } \\
\hline $\begin{array}{l}\text { Rheumatic diseases } \\
\text { Musculoskeletal system } \\
\text { Cardiovascular system } \\
\text { Gastrointestinal system } \\
\text { Dysmetabolic } \\
\text { Neurologic } \\
\text { Infectious } \\
\text { Others }\end{array}$ & $664(95.4)$ & $\begin{array}{l}19(11.3) \\
57(33.9) \\
16(9.5) \\
20(11.9) \\
5(3) \\
14(8.3) \\
3(1.8) \\
34(20.3)\end{array}$ & $\begin{array}{l}34(16) \\
72(33.8) \\
19(8.9) \\
22(10.3) \\
3(1.4) \\
17(8) \\
3(1.4) \\
43(20.2)\end{array}$ & $\begin{array}{l}27(21.8) \\
40(32.2) \\
6(4.8) \\
10(8.1) \\
1(0.8) \\
23(18.6) \\
3(2.4) \\
14(11.3)\end{array}$ & $\begin{array}{l}33(20.8) \\
69(43.4) \\
3(1.9) \\
17(10.7) \\
2(1.3) \\
10(6.2) \\
3(1.9) \\
22(13.8)\end{array}$ & 0.004 \\
\hline \multicolumn{7}{|l|}{ Most frequent sites of pain } \\
\hline $\begin{array}{l}\text { Head/neck } \\
\text { Posterior Chest } \\
\text { Anterior Chest } \\
\text { Abdominal } \\
\text { Muscles } \\
\text { Joints } \\
\text { Pelvis }\end{array}$ & $663(95.3)$ & $\begin{array}{l}9(5.3) \\
25(14.8) \\
17(10.1) \\
44(26) \\
34(20.1) \\
38(22.5) \\
2(1.2)\end{array}$ & $\begin{array}{l}16(7.5) \\
27(12.7) \\
19(8.9) \\
48(22.5) \\
45(21.1) \\
54(25.3) \\
4(1.9)\end{array}$ & $\begin{array}{l}14(11.3 \\
24(19.3) \\
11(9.9) \\
22(17.7) \\
30(24.1) \\
21(16.9) \\
2(1.6)\end{array}$ & $\begin{array}{l}19(12.1) \\
37(23.6) \\
9(5.7) \\
37(23.6) \\
18(11.5) \\
34(21.7) \\
3(1.9)\end{array}$ & 0.08 \\
\hline \multicolumn{7}{|c|}{ Psychiatric disorders associated } \\
\hline $\begin{array}{l}\text { Anxiety } \\
\text { Depression } \\
\text { Sleeplessness } \\
\text { Somatization } \\
\text { Personality disorders } \\
\text { Others }\end{array}$ & $665(95.5)$ & $\begin{array}{l}84(49.7) \\
35(20.7) \\
26(15.4) \\
13(7.7) \\
7(4.1) \\
4(2.4)\end{array}$ & $\begin{array}{l}94(44.1) \\
50(23.5) \\
27(12.7) \\
20(9.4) \\
10(4.7) \\
12(5.6)\end{array}$ & $\begin{array}{l}49(39.5) \\
20(16.2) \\
27(21.8) \\
18(14.5) \\
5(4) \\
5(4)\end{array}$ & $\begin{array}{l}104(65.4) \\
20(12.6) \\
16(10.1) \\
10(6.3) \\
4(2.5) \\
5(3.1)\end{array}$ & 0.002 \\
\hline
\end{tabular}

disorders underlying the non-oncological pain, specific pain types, anatomical sites of pain, and comorbidities associated with pain observed in clinical practice.

There was a significant difference between geographical regions in terms of reports of acute and chronic pain: acute pain was more frequent in the South (63.5\%), while chronic pain was more frequent in the Central region (32.3\%; p=0.0008). Additionally, chronic oncological pain was more frequent in the Northeast $(29.6 \%)$, while chronic non-oncological pain was more frequent in the Central region $(33.9 \%$; $\mathrm{p}=0.0001)$.
The underlying pain disorders reported were also different between geographical regions; rheumatic pain $(21.8 \%)$ and neurological pain $(18.6 \%)$ were more frequent in the Central region, while musculoskeletal pain was significantly more frequent in the South $(43.4 \% ; \mathrm{p}=0.004)$. Overall, chronic pain conditions were most relevant in rheumatological disease (arthritis, fibromyalgia, and osteoarthritis; 42.98\%), low back pain (LBP; 44.67\%), and diabetic neuropathic pain $(74.36 \%$; $<<0.001)$.

There were no differences in the anatomical sites of pain among the geographical regions $(p=0.08)$. However, the 
reported comorbidities associated with pain had different distributions among the regions $(\mathrm{p}=0.002)$, with anxiety being more common in the South $(65.4 \%)$, depression in the Northeast (23.5\%), and sleep disorders (21.8\%) and somatization (14.5\%) in the Central region.

\section{Types of Drugs, Administration Routes, and Adjuvants}

There were no differences in the use of paracetamol or non-steroidal anti-inflammatory drugs (NSAIDs) such as ketorolac $(p=0.14)$ between regions. However, codeine + paracetamol was most frequently prescribed in the Northeast $(67.6 \%)$ and less frequently prescribed in the South $(44.0 \%)$. Tramadol and fentanyl were more frequently prescribed in the South $(27 \%$ and $18.2 \%$, respectively), while morphine was more frequently prescribed in the Central region $(9.7 \% ; \mathrm{p}=0.0005)$ (Table 2). Regarding drug combinations, tramadol + paracetamol was more frequently prescribed in the South $(69.5 \%)$ and codeine + paracetamol was more frequently prescribed in the Northeast $(67.6 \% ; \mathrm{p}=0.0001)$.

Regarding the administration routes, the most frequently used types were oral tablets in the Central region $(37.1 \%)$, the Northwest (14.8\%), and the Northeast (14.6\%), suppositories in the Northwest (4.7\%), pain relief plasters in the Central region $(11.7 \%)$, and intramuscular/ intravenous injections in the South $(51.6 \% ; \mathrm{p}=0.017)$.

Overall, when pain was treated with the weak opioids codeine or tramadol/tapentadol, adjuvants were used in $57.7 \%$ and $20.6 \%$ of cases, respectively, and when pain was treated with fentanyl or morphine, adjuvants were used in $11.4 \%$ or $7.8 \%$ of cases, respectively. The most frequently used adjuvants were the anticonvulsants gabapentin and pregabalin, which were used in $58 \%$ of cases involving adjuvants; this was followed by antidepressants (tricyclic antidepressants [TCAs], such as amitriptyline, and serotonin-norepinephrine reuptake inhibitors [SNRIs], such as duloxetine), which were used in $35.3 \%$ of cases. Regarding the patients treated with pain medications, anxiety was the most frequent mental health (in $48.4 \%$ of cases) followed by depression (19.4\%) and then sleep disorders $(15.2 \%)$.

\section{Pain Type Among Patients with Anxiety and Comorbidities by Pain Type}

Regarding patients with anxiety, acute pain was the most frequently reported pain type $(60.82 \%)$, followed by oncological pain $(23.10 \%)$ and then chronic pain $(16 \%$; $\mathrm{p}<0.001$ ).

Comorbidities that were more common in acute pain than chronic pain were sleep disorders and somatization (43.56\% and $53.12 \%$, respectively), while comorbidities that were more common in chronic pain than acute pain were depression and mood disorders $(37.88 \%$ and $56 \%$, respectively; $\mathrm{p}<0.001$ ) (Table 3).

\section{Discussion}

The present study showed that psychological disorders are frequently reported with pain in daily nursing practice; anxiety, depression, and sleep disorders were the most frequent problems among the patients with pain. However, the purpose of this study was to report on the personal perceptions of nurses and to investigate "reallife" epidemiological reports and treatment strategies among different clinical settings and geographical regions.

Specific education about pain management nursing is essential for nurses, as they play an important role in pain management. Promotion of optimal nursing care for people affected by pain is the main focus of pain management nursing. ${ }^{8}$ Unfortunately, targeted education on pain management has not been emphasized in education programs for nurses and other healthcare professionals and these programs remain insufficient. ${ }^{7,9}$ Pain relief is a fundamental right of each person; nurses, as healthcare providers, have a central role in this context. ${ }^{10}$ In the code of ethics of Italian nurse, time spent with the patient should always involve patientcentered care: in this context, nurses should play major roles in accurate pain assessment, which should involve consideration of the associated psychological and sociocultural implications. ${ }^{11}$

\section{Pain Types and Associated Comorbidities}

Our data show that among patients with acute pain, anxiety and sleep disorders were more common than depressive syndromes. In contrast, among patients with chronic pain, whether related to oncological or chronic disorders, the scenario is reversed, with depression being the most frequent psychological disorder.

In clinical practice, an effective pain treatment is not based exclusively on the administration of analgesic drugs, but also on the correct routine assessment of pain. ${ }^{12}$ Untreated or unrelieved pain involving tissue or nerve injury can lead to maladaptive neuroplastic modifications in the dorsal horn of the spinal cord and at the supraspinal level in the cortex, involving increased pain sensitivity and leading to neuropathic 
Table 2 Distribution of drug use in geographic areas considered

\begin{tabular}{|c|c|c|c|c|c|c|}
\hline Variable & Total Responders No. (\%) & North-West No. (\%) & North-East No. (\%) & Centre No. (\%) & South No. (\%) & $\mathbf{p}$ \\
\hline Paracetamol & 665 (95.5) & $125(74)$ & $|5|(70.9)$ & $82(66.1)$ & $109(68.6)$ & 0.14 \\
\hline NSAIDs & & 31 (18.3) & $42(19.7)$ & $32(25.8)$ & $26(16.3)$ & \\
\hline Ketorolac & & $13(7.7)$ & $20(9.3)$ & $10(8.1)$ & $24(15.1)$ & \\
\hline Codeine+paracetamol & $665(95.5)$ & $90(53.2)$ & $144(67.6)$ & $76(61.3)$ & $70(44)$ & 0.0005 \\
\hline Tramadol & & $39(23.1)$ & $36(16.9)$ & $23(18.6)$ & $43(27)$ & \\
\hline Fentanyl & & $27(16)$ & $13(6.1)$ & $9(7.2)$ & $29(18.2)$ & \\
\hline Morphine & & $9(5.3)$ & $15(7)$ & $12(9.7)$ & $15(9.4)$ & \\
\hline Other ${ }^{\mathrm{h}}$ & & $4(2.4)$ & $5(2.3)$ & $4(3.2)$ & $2(1.2)$ & \\
\hline Combinations & $658(94.5)$ & & & & & \\
\hline Tramadol+paracetamol & & $81(48.2)$ & $101(47.6)$ & $55(44.39$ & $107(69.5)$ & 0.001 \\
\hline Codeine+paracetamol & & $78(46.4)$ & $103(48.6)$ & $59(47.6)$ & $4 I(26.5)$ & \\
\hline Caffeine+paracetamol & & $3(1.8)$ & $2(1)$ & $3(2.4)$ & $0(0)$ & \\
\hline Other ${ }^{i}$ & & $6(3.6)$ & $6(2.8)$ & $7(5.7)$ & $6(3)$ & \\
\hline Adjuvants & 637 (91.59) & & & & & \\
\hline Amitriptyline & & $44(26.3)$ & $65(31.2)$ & $4 \mid(33.1)$ & $44(31.9)$ & 0.09 \\
\hline Duloxetine & & $6(3.6)$ & $8(3.9)$ & $5(4)$ & $4(2.9)$ & \\
\hline Gabapentin & & $67(40.1)$ & $103(49.5)$ & $49(39.5)$ & $56(40.6)$ & \\
\hline Pregabalin & & $40(24)$ & $19(9.1)$ & $22(17.7)$ & $22(15.9)$ & \\
\hline Bisphosphonates & & $10(6)$ & $13(6.2)$ & $7(5.7)$ & $12(8.7)$ & \\
\hline
\end{tabular}

Notes: (h) Oxycodone or buprenorphine or methadone; (i) Oxycodone + paracetamol or oxycodone + naloxone.

Table 3 Pain modality and comorbidities

\begin{tabular}{|c|c|c|c|c|c|}
\hline Variable & Total No. (\%) & Chronic/Non-Oncological Pain No. (\%) & Cancer No. (\%) & Acute No. (\%) & $\mathbf{p}$ \\
\hline \multicolumn{6}{|l|}{ Psychiatric disorders } \\
\hline $\begin{array}{l}\text { Anxiety } \\
\text { Depression } \\
\text { Sleeplessness } \\
\text { Somatization } \\
\text { Mood disorders } \\
\text { Others }\end{array}$ & $690(100)$ & $\begin{array}{l}55(31.8) \\
50(28.9) \\
31(17.9) \\
18(10.4) \\
14(8.9) \\
5(2.8)\end{array}$ & $\begin{array}{l}79(47.6) \\
41(24.7) \\
26(15.6) \\
12(7.2) \\
2(1.2) \\
6(3.6)\end{array}$ & $\begin{array}{l}208(59.2) \\
41(11.68) \\
44(12.5) \\
34(9.7) \\
9(2.5) \\
15(4.3)\end{array}$ & $<0.0001$ \\
\hline \multicolumn{6}{|l|}{ Pathologies associated } \\
\hline $\begin{array}{l}\text { Rheumatic } \\
\text { Musculoskeletal system } \\
\text { Cardiovascular system } \\
\text { Gastrointestinal system } \\
\text { Dysmetabolic } \\
\text { Neurologic } \\
\text { Infectious } \\
\text { Others }\end{array}$ & $\begin{array}{l}689 \\
(99.8)\end{array}$ & $\begin{array}{l}37(21.5) \\
62(36.1) \\
9(5.2) \\
9(5.2) \\
10(5.8) \\
26(15.1) \\
3(1.7) \\
16(9.3)\end{array}$ & $\begin{array}{l}39(23.5 \\
61(36.7 \\
9(5.4 \\
23(13.8 \\
0(0) \\
22(13.2) \\
3(1.8) \\
9(5.4)\end{array}$ & $\begin{array}{l}45(12.8) \\
|2|(34.5) \\
29(8.3) \\
38(10.8) \\
I(0.3) \\
18(5.1) \\
7(2.0) \\
92(26.2)\end{array}$ & 0.0001 \\
\hline
\end{tabular}

pain. ${ }^{13}$ Untreated pain may produce various long-term effects such as decreased pain thresholds, maladaptive behaviors, substance use disorders, vulnerability to stress disorders, and anxiety despite the resolution of pain. ${ }^{14}$ Pain can have several physiopathological causes. With appropriate assessment, a multimodal treatment plan can be developed, involving pharmacological and non-pharmacological interventions.
Adequate monitoring of pain therapy is also important to guarantee safety and effectiveness of pain management.

As there is a considerable association between pain (acute or persistent) and anxiety, physicians are encouraged to screen patients for anxiety. For example, the US Centers for Disease Control and Prevention (CDC) recently published guidelines on opioid prescribing, which recommended screening for 
anxiety as a component of a comprehensive pain assessment. $^{15,16}$ Persistent pain is maladaptive; it no longer serves as a warning signal, and healing has occurred. However, persistent pain can lead to significant emotional distress along with impaired social and physical functioning. Anxiety disorders have been found to be common in patients with various persistent pain problems, including diabetic neuropathic pain, migraines and other headaches, chest pain, stomach pain, and musculoskeletal pain (including fibromyalgia, arthritic pain, neck pain, LBP, and pelvic pain). ${ }^{17-22}$

The prevalence of chronic pain ranges from $2 \%$ to $40 \%$ in patients with mental health disorders, and the prevalence of mental health disorders in patients with pain ranges from $17 \%$ to $29 \% .^{23,24}$ This overlap seems to suggest a bidirectional relationship between pain and mental health disorders. As shown by epidemiological and functional imaging studies, this "pain matrix" may be partly mediated by shared neural mechanisms. ${ }^{25}$ In light of these considerations, the use of analgesics and adjuvants, both for pain syndromes and mental disorders, should be considered as first-line drugs for patients with chronic pain. $^{26}$

Medical research has taken us far, but for patients with persistent pain, the nursing discipline is tasked with the challenge of improving patient care and outcomes (including quality of life). A systematic review and meta-analysis regarding the prevalence of persistent pain estimated that persistent musculoskeletal pain or chronic widespread pain affects $10-15 \%$ of the general population. ${ }^{16}$ Additionally, persistent pain with neuropathic characteristics has a reported prevalence of $0.9-17.9 \%$ (median: $9.4 \%$ ), ${ }^{27}$ and it occurs more frequently in patients with cancer, human immunodeficiency virus (HIV) infection, postherpetic neuralgia, and diabetic peripheral neuropathy. ${ }^{22}$ Furthermore, chronic LBP has been reported to affect 9.4\% of people (CI 95\%: 9.0-9.8), and it was ranked as the greatest contributor to global disability out of 291 conditions based on years lived with disability (YLDs) and sixth in terms of overall disability based on disabilityadjusted life years (DALYs). The prevalence and severity of LBP increase with age. ${ }^{28}$ Musculoskeletal disorders are among the most prevalent causes of pain in older adults. $^{25,26}$

The physiopathology of chronic persistent pain remains the subject of intense research. The impact of persistent pain on people's lives motivates clinical practitioners, neuroscientists, and integrative medicine researchers to work in order to resolve the problems that patients with persistent pain face.

A high prevalence of persistent pain occurs in patients with post-traumatic stress disorder (PTSD), which causes distress and impairment regarding social, occupational, and marital roles, and regarding other aspects of life. It has been postulated that uncontrolled pain following physical injury is the core trauma in PTSD and that PTSD and persistent pain may be mutually-reinforcing conditions. Therefore, an evaluation for PTSD is warranted in all patients with persistent pain.

Among the vast majority of the nurses in this study, acute pain was easily recognized as a "symptom" or a recurrent acute spike in a painful disease. In contrast, identification and classification of chronic pain was a major challenge for many of the participating nurses. Chronic pain was reported in the Northeast of Italy, where pain is considered scientifically as a factor that must be recognized and promptly and adequately treated, just as acute pain usually is (Table 1). In contrast, chronic pain was underestimated in all other regions, possibly due to sociocultural differences.

Nurses in the Central region reported treating the pain of patients affected by rheumatic and neurological disorders more frequently than nurses in other regions; in this region, professional nurses have achieved a high degree of expertise and excellence regarding the management of patients affected by spinal cord injuries, stroke, primary or secondary motor neuron disorders, or severe disabling diseases of the immuno-connective system. The participating nurses were asked to report on the comorbidities associated with various types of pain in individual patients. A clear-cut higher prevalence of the comorbidity anxiety (which may be related to reactions to sudden unexpected acute pain in alert patients) was observed in the South compared to in the other regions. Conversely, in the Northeast and Northwest, more attention was paid to chronic pain, which was often associated with higher levels of depression and lower mood, which are characteristic of chronic progressive diseases (Table 1).

\section{Treatment Strategies}

Pain is the most common "nursing diagnosis" across the continuum of care, among inpatients, patients undergoing rehabilitation, outpatients, and patients in home settings. ${ }^{29}$ Among the professional healthcare providers, nurses are permitted to identify signs and symptoms and to administer new disease-modifying or palliative treatments to 
patients who are unresponsive to current treatment; moreover, they should administer pain control treatments when a pathological condition causes excessive suffering that impairs the patient's dignity and quality of life.

The results regarding drug administration indicate that NSAIDs (for example, ketorolac) are widely used in Italy as urgent pain relief in post-surgical patients, without significant geographical differences. Opioids (weak or strong and alone or combined with paracetamol) are relatively evenly used across Italy, as the statistical differences in the use of specific analgesics observed among the different geographical regions have only minor clinical relevance (Table 2).

NSAID use is limited by undesired side effects on the gastrointestinal, hematological, renal, and cardiovascular systems. These undesired side effects can be reduced by using topical rather than oral NSAIDs, with emerging technologies developing longer-acting and betterpenetrating forms of these medications. ${ }^{30}$ These technologies are transforming the way a variety of medications currently used for pain will be applied to the skin. ${ }^{31,32}$ Improved analgesia may soon be achieved based on a variety of topical agents, including gabapentin, amitriptyline, ketamine, lidocaine, capsaicin, turmeric, clonidine, and botulinum toxin type A. ${ }^{33,34}$

The questionnaire data on analgesic drug use also indicated that the World Health Organization (WHO) three-step model for pain treatment ${ }^{35}$ is widely used. Miceli et al reported that opioids are used less in Italy than in other countries, with $0.7 \%$ of the Italian population being treated with opioids (which is low given the percentage of chronic pain patients in Italy), and $>50 \%$ of opioid prescriptions involve weak opioids (codeine or tramadol), independent of the application of Italian Law 38/2010. ${ }^{36}$

The drugs reported by the participating nurses seem to provide a similar level of analgesia, with none of them having an absolute clinical advantage over the others; therefore, local experience and availability of drugs should also be considered when prescribing analgesia.

We found that acute pain was treated more frequently than chronic pain in the South, while chronic pain was treated more frequently in the Central, Northeast, and Northwest regions. This finding was reported in our previous study, ${ }^{7}$ highlighting the existence of a divide between the Central/North regions versus the South. This divide is particularly evident in terms of pain assessment using validated scales, knowledge of Italian Law 38/2010, and access to specific training regarding pain management.
This lack of geographical uniformity is attributable to the health service organization in Italy, with each individual region being autonomous regarding their health policies. Developing an extensive national public campaign to promote safer medication use by healthcare providers and patients and providing equitable and optimal care to all patients with pain, all over Italy, is necessary. Focusing on the elimination of health disparities would influence the availability and effectiveness of pain management in general. Additionally, increasing education and training related to pain care and pain care disparities in basic medicine, nursing, and allied health professional education programs, as well as in continuing education programs, ${ }^{37}$ and providing targeted training in pain care disparities for all healthcare providers ${ }^{7,38}$ is necessary.

\section{Limitations}

The questionnaire participants may not be a representative sample of all nurses in Italy. Indeed, only a relatively small group of nurses were aware of and strongly motivated to participate in the survey. Therefore, a possible limitation is that, as the questionnaire was not filled in by a specifically selected group of nurses (selected, for example, according to their work settings), the distribution of the participants across the regions analyzed could be subject to unknown biases. Drawing any definitive conclusion on differences between geographical regions is difficult. Cross-sectional studies are now needed to investigate the precise rates of psychological comorbidities using measuring instruments (questionnaires and other tests), the prescription and administration of new analgesic medications, the full application of Italian Law 38/2010, the role of nurses in the regional and national management of pain, and the usefulness of training in this field.

\section{Conclusions}

Pain can represent an emergency that requires a multidisciplinary approach. In this setting, nurses play a central role as they are directly involved in the holistic care of the patient with oncological or non-oncological pain.

Our investigation of the treatment of pain in "real-life" Italian settings essentially shows that pain is treated according to the dictates of the WHO three-step model and the most common national and supranational guidelines. Furthermore, taking care of a patient with pain seems to generally include consideration of the psychological aspects, via the diagnosis and treatment of the most 
common related disorders: anxiety, depression and sleep disorders.

In Italy, the role of nurses in pain relief is recognized by Italian Law 38/2010 (article 5, paragraph 2). Nurses, therefore, are recognized as essential professional figures in palliative care and non-oncological pain management.

Pain assessment is a fundamental step for preparing individualized therapeutic plans. Thus, pain should be considered a vital parameter and assessed several times per day.

Nowadays, the duty of nurses should involve personalized, complex care and research processes in order to improve the quality of life of suffering patients. Nurses are increasingly overcoming stereotypes and gaining recognition as invaluable team members who provide patient-centered pain treatment tailored to the context of pain in the patient's everyday life. What has become clear in the early $21 \mathrm{st}$ century is that no single professional discipline alone can solve the mysteries or resolve the complex problems created by severe or persistent pain. Nurses are a major and underutilized component of the healthcare workforce, and their leadership is needed to solve clinical problems, redesign systems, and improve healthcare environments.

\section{Ethics and Consent}

IRB or ethics committee: Not applicable. Participation in the online survey was anonymous and voluntary, and no written consent was requested from the participants. No ethical committee review was necessary because no sensitive data that would allow the participants to be immediately identified were requested in the online questionnaire. In addition, the questionnaire was previously submitted for validation and approval by the scientific societies that promoted it to their members.

\section{Acknowledgments}

The authors wish to acknowledge the assistance of the following organizations and individuals: Paolo Procacci Foundation (FPP), Italian Association for the Study of Pain (AISD), National Nurse Federation (IPASVI), and Mrs. Lorenza Saini for web assistance and survey promotion.

\section{Author Contributions}

All authors contributed to data analysis, drafting or revising the article, gave final approval of the version to be published, and agree to be accountable for all aspects of the work.

\section{Funding}

No financial support was received to perform this study.

\section{Disclosure}

The authors report no conflicts of interest in this work.

\section{References}

1. Pasero C, Quinlan-Colwell A, Rae D, Broglio K, Drew D. American Society for Pain Management nursing position statement: prescribing and administering opioid doses based solely on pain intensity. Pain Manag Nurs. 2016;17(3):170-180. doi:10.1016/j.pmn.2016.03.001

2. American Nurses Association. Code of Ethics for Nurses with Interpretive Statements. Silver Spring, MD: Nursesbooks.org; 2015.

3. Correa-de-Araujo R. Evidence-based practice in the United States: challenges, progress, and future directions. Health Care Women Int. 2016;37(1):2-22. doi:10.1080/07399332.2015.1102269

4. Brennan F, Carr DB, Cousins M. Pain management: a fundamental human right. Anesth Analg. 2007;105(1):205-221. doi:10.1213/01. ane. 0000268145.52345 .55

5. Adams LM, Turk DC. Psychosocial factors and central sensitivity syndromes. Current Rheumatology Rev. 2015;11(2):96-108. doi:10.2174/1573397111666150619095330

6. American Psychiatric Association (APA). Diagnostic and Statistical Manual of Mental Disorders. 5th ed. Arlington, VA: American Psychiatric Association; 2013.

7. Angeletti C, Guetti C, Paesani M, Colavincenzo S, Ciccozzi A, Angeletti PM. An analysis of Italian nurses' approach to patients' pain: a nationwide online survey. Pain Res Manag. 2018;2018:5165262. doi:10.1155/2018/5165262

8. Doorenbos AZ, Gordon DB, Tauben D, et al. A blueprint of pain curriculum across prelicensure health sciences programs: one $\mathrm{NIH}$ pain consortium center of excellence in pain education (CoEPE) experience. $J$ Pain. 2013;14(12):1533-1538. doi:10.1016/j. jpain.2013.07.006

9. American Society for Pain Management Nursing \& American Nurses Association. Pain Management Nursing: Scope \& Standards of Practice. 2nd ed. Silver Spring, MD: Nursesbooks.org; 2016.

10. Ferrell B. Ethical perspectives on pain and suffering. Pain Management Nursing. 2005;6(3):83-90. doi:10.1016/j.pmn.2005.06.001

11. Flaskerud JH. Pain, culture, assessment, and management. Issues Ment Health Nurs. 2015;36(1):74-77. doi:10.3109/01612840.2014.932873

12. American Society of Anesthesiologists Task Force on Acute Pain Management. Practice guidelines for acute pain management in the perioperative setting: an updated report by the American Society of Anesthesiologists task force on acute pain management. Anesthesiology. 2012;116(2):248-273. doi:10.1097/ALN.0b013e31823c1030

13. West SJ, Bannister K, Dickenson AH, Bennett DL. Circuitry and plasticity of the dorsal horn - toward a better understanding of neuropathic pain. Neuroscience. 2015;300:254-275. doi:10.1016/j. neuroscience.2015.05.020

14. Mathews L. Pain in children: neglected, unaddressed and mismanaged. Indian J Palliat Care. 2011;17(Suppl):S70-S73. doi:10.4103/0973-1075.76247

15. Dowell D, Haegerich TM. Using the CDC guideline and tools for opioid prescribing in patients with chronic pain. Am Fam Physician. 2016;93(12):970-972.

16. Henschke N, Kamper SJ, Maher CG. The epidemiology and economic consequences of pain. Mayo Clin Proc. 2015;90(1):139-147. doi:10.1016/j.mayocp.2014.09.010

17. Kudlow PA, Rosenblat JD, Weissman CR, et al. Prevalence of fibromyalgia and co-morbid bipolar disorder: a systematic review and meta-analysis. J Affect Disord. 2015;188:134-142. doi:10.1016/j. jad.2015.08.030 
18. Demyttenaere K, Bruffaerts R, Lee S, et al. Mental disorders among persons with chronic back or neck pain: results from the world mental health surveys. Pain. 2007;129(3):332-342. doi:10.1016/j. pain.2007.01.022

19. Reme SE, Tangen T, Moe T, Eriksen HR. Prevalence of psychiatric disorders in sick listed chronic low back pain patients. Eur J Pain. 2011;15(10):1075-1080. doi:10.1016/j.ejpain.2011.04.012

20. Von Korff M, Crane P, Lane M, et al. Chronic spinal pain and physical-mental comorbidity in the United States: results from the national comorbidity survey replication. Pain. 2005;113(3):331-339. doi:10.1016/j.pain.2004.11.010

21. Van Oudenhove L, Törnblom H, Störsrud S, Tack J, Simrén M. Depression and somatization are associated with increased postprandial symptoms in patients with irritable bowel syndrome. Gastroenterology. 2016;150(4):866-874. doi:10.1053/j. gastro.2015.11.010

22. Naranjo C, Del Reguero L, Moratalla G, Hercberg M, Valenzuela M, Failde I. Anxiety, depression and sleep disorders in patients with diabetic neuropathic pain: a systematic review. Expert Rev Neurother. 2019;4:1-9.

23. Steel Z, Marnane C, Iranpour C, et al. The global prevalence of common mental disorders: a systematic review and meta-analysis 1980-2013. Int J Epidemiol. 2014;43(2):476-493. doi:10.1093/ije/ dyu038

24. Hooten WM. Chronic pain and mental health disorders: shared neural mechanisms, epidemiology, and treatment. Mayo Clin Proc. 2016;91 (7):955-970. doi:10.1016/j.mayocp.2016.04.029

25. Garcia-Larrea L, Peyron R. Pain matrices and neuropathic pain matrices: a review. Pain. 2013;154(Suppl 1):S29-S43. doi:10.1016/ j.pain.2013.09.001

26. Mansfield K, Sim J, Jordan JL, Jordan KP. A systematic review and meta-analysis of the prevalence of chronic widespread pain in the general population. Pain. 2016;157(1):55-64. doi:10.1097/j. pain.0000000000000314

27. Hoy D, March L, Woolf A, et al. The global burden of neck pain: estimates from the global burden of disease 2010 study. Ann Rheum Dis. 2014;73(7):1309-1315. doi:10.1136/annrheumdis-2013-204431
28. Heikkinen J, Honkanen R, Williams L, et al. Depressive disorders, anxiety disorders and subjective mental health in common musculoskeletal diseases: a review. Maturitas. 2019;127:18-25. doi:10.1016/j. maturitas.2019.05.011

29. Jomar RT. The most common nursing diagnosis among adults/seniors hospitalised with cancer: integrative review. E Cancer Medical Sci. 2014;8:462.

30. Derry S, Moore RA, Gaskell H, McIntyre M, Wiffen PJ. Topical NSAIDs for acute musculoskeletal pain in adults. Cochrane Database Syst Rev. 2017;5:CD008609.

31. Limón D, Amirthalingam E, Rodrigues M, et al. Novel nano structured supramolecular hydrogels for the topical delivery of anionic drugs. Eur J Pharm Biopharm. 2015;96:421-436. doi:10.1016/j. ejpb.2015.09.007

32. Peptu C, Rotaru R, Ignat L, et al. Nano technology approaches for pain therapy through transdermal drug delivery. Curr Pharm Des. 2015;21(42):6125-6139. doi:10.2174/1381612821666151027152752

33. Allegri M, Baron R, Hans G, et al. A pharmacological treatment algorithm for localized neuropathic pain. Curr Med Res Opin. 2016;32(2):377-384. doi:10.1185/03007995.2015.1129321

34. Mercadante S. Topical amitriptyline and ketamine for the treatment of neuropathic pain. Expert Rev Neurother. 2015;15(11):1249-1253. doi:10.1586/14737175.2015.1101347

35. Nguyen TA, Friedman AJ. Curcumin: a novel treatment for skin-related disorders. J Drugs Dermatol. 2013;12(10):1131-1137.

36. Miceli L, Bednarova R, Di Cesare M, et al. Outpatient therapeutic chronic opioid consumption in Italy - a one-year survey. Minerva Anestesiol. 2017;83:33-40.

37. World Health Organization. Cancer Pain Relief. 2nd ed. Genève: World Health Organization; 1996.

38. Meghani SH, Polomano RC, Tait RC, Vallerand AH, Anderson KO, Gallagher RM. Advancing a national agenda to eliminate disparities in pain care: directions for health policy, education, practice, and research. Pain Med. 2012;13(1):5-28. doi:10.1111/j.15264637.2011.01289.x
Journal of Pain Research

\section{Publish your work in this journal}

The Journal of Pain Research is an international, peer reviewed, open access, online journal that welcomes laboratory and clinical findings in the fields of pain research and the prevention and management of pain. Original research, reviews, symposium reports, hypothesis formation and commentaries are all considered for publication. The manuscript management system is completely online and includes a very quick and fair peer-review system, which is all easy to use. Visit http:// www.dovepress.com/testimonials.php to read real quotes from published authors. 